\title{
Organized Innovation: A Framework for Effectively Managing Innovation
}

\section{Dr. Sara Jansen Perry, Baylor University}

Sara Jansen Perry is an assistant professor of management in the Hankamer School of Business at Baylor University. She teaches organizational behavior and human resource management courses, including negotiation and principles of management. She earned her PhD in 2009 from the University of Houston in Industrial-Organizational Psychology, also earning the Meredith P. Crawford fellowship in I-O Psychology from HumRRO that year. In the 2013-14 academic year, she held the Professional Land Management (PLM) endowed professorship at the University of Houston-Downtown. Sara conducts research in innovation, leadership, and stress-related topics.

\section{Dr. Emily M Hunter, Baylor University}

Emily M. Hunter, Assistant Professor of Management in the Hankamer School of Business at Baylor University, earned her Ph.D. in Industrial-Organizational Psychology at the University of Houston in 2009. She teaches negotiation and conducts research on work-family conflict, employee deviance and servant leadership.

\section{Prof. Steven C. Currall, University of California, Davis}

Steve Currall is the Chancellor's Advisor and Professor of Management at the University of California, Davis. As Chancellor's Advisor, he is leading the process for creating a new UC Davis campus in the Sacramento region to advance the university's public policy, education, business, and outreach programs. He also serves as Chief Strategic Advisor, and member of the Executive Committee and Board of Directors, for the ten-campus University of California Global Health Institute. He previously served for five years as the Dean of the Graduate School of Management at UC Davis. A behavioral scientist, Currall has conducted research and taught for over 25 years on organizational psychology topics such as innovation, emerging technologies, negotiation, and corporate governance. He is a Fellow of the American Association for the Advancement of Science.

At the invitation of the U.S. President's Council of Advisors on Science and Technology, Currall was a member of the Nanotechnology Technical Advisory Group. He has been a grantee on $\$ 21,533,893$ in external funding of which over $78 \%$ came from refereed research grants from the National Science Foundation (NSF) and National Institutes of Health. Currall was lead author of a book on universitybusiness-government collaboration entitled, Organized Innovation: A Blueprint for Renewing America's Prosperity (Oxford University Press, 2014). Based on a study funded by the NSF, the book is the culmination of a 10-year research project on interdisciplinary research involving science, engineering, and medicine. He has served as a member of editorial review boards such as Academy of Management Review, Academy of Management Journal, and Organization Science.

In addition to positions in schools of management, he has served in engineering schools as vice dean, department chair, and endowed chair holder; he has also held faculty appointments in a Department of Psychology and in a Department of Statistics. He was formerly Vice Dean of Enterprise and Professor of Management Science and Innovation in the Faculty of Engineering Sciences at University College London (UCL). He was Visiting Professor of Organisational Behaviour and Entrepreneurship at London Business School. At UCL, he was founding Chair of the Department of Management Science and Innovation. In 2003, he was a Visiting Scholar at the University of Chicago's Booth School of Business.

At Rice University, Currall was the William and Stephanie Sick Professor of Entrepreneurship in the Brown School of Engineering and tenured Associate Professor of Management, Psychology, and Statistics in the Jones Graduate School of Management. He was Founding Director of the Rice Alliance for Technology and Entrepreneurship, which is a Rice University education and research center that is a partnership of the Schools of Engineering, Management and Natural Sciences. During Currall's five-year tenure leading the Alliance, it assisted in the launch of over 160 technology start-up companies, which raised in excess of $\$ 300,000,000$ in equity capital. Currall also founded the Rice University Business Plan 
Competition, which involved the largest number of competing universities (36) and richest prize money $(\$ 325,000)$ of any graduate student business plan competition in the world.

Currall received Stanford University's Price Foundation Innovative Entrepreneurship Educator Award, Ernst \& Young's regional Entrepreneur of the Year Award@, and the Grand Velocity Award for Academic Entrepreneurship, Indiana University. He has advised organizations such as Schlumberger, BMC Software, BP, and Shell. He has been quoted over 600 times in publications such as the New York Times, Wall Street Journal, Washington Post, Financial Times, Business Week, British Broadcasting Corporation (BBC) television, and the Nightly Business Report. He earned a Ph.D. from Cornell University, a M.Sc. from the London School of Economics and Political Science (as a Rotary International Scholar), and a B.A. (cum laude) from Baylor University.

\section{Mr. Ed Frauenheim, The Great Place to Work Institute}

Ed Frauenheim has been a writer, editor and commentator for nearly 20 years. He has focused on the intersection of work, technology and society. He is co-author of two books: Good Company: Business Success in the Worthiness Era and Organized Innovation: A Blueprint for Renewing America's Prosperity. Ed currently is an editor at the Great Place to Work Institute, which works to improve society by transforming workplaces. Prior to this role, he has been a journalist at publications including Workforce magazine, CNET News.com and The Oakland Tribune. He has contributed articles to publications including Wired, Salon.com, The San Jose Mercury News, The San Diego Union-Tribune and The Seattle Times.

Ed's stories have earned honors from American Business Media, the American Society of Business Publication Editors, the Associated Press News Executive Council of California and Nevada, and the Northern California Chapter of the Society of Professional Journalists. In addition, Good Company earned the 2012 Gold Nautilus Book Award in the Business/Leadership category.

Ed has spoken to live and broadcast audiences on subjects including corporate social responsibility, management and technology.

Along with Organized Innovation co-authors Sara Jansen Perry and Emily M. Hunter, Ed delivered a day-long workshop on the principles of the book to affiliates of the Baylor Research and Innovation Collaborative at Baylor University.

Ed graduated cum laude from Princeton University with a degree in History. He earned a Master's Degree in Education from the University of California at Berkeley.

Ed lives in San Francisco with his wife and two kids. 


\title{
Organized Innovation: A Framework for Effectively Managing Innovation
}

\author{
ABSTRACT \\ The future of American innovation leadership is not as certain as in the past. Notably, China has \\ dominated in recent years (e.g., increased patent filings by 24 percent in 2012, compared to only \\ 7.8 percent in the $\mathrm{US}^{83}$ ). One solution is to increase understanding about the best way to manage \\ innovation efforts, starting with education of new and seasoned engineering managers. To that \\ end, we offer a theoretical framework, Organized Innovation, which is based on our decade-long \\ qualitative and quantitative research on National Science Foundation (NSF) Engineering \\ Research Centers (ERCs). The framework is focused on what research leaders can do to create \\ organizational conditions ripe for innovation success. We organize our prescriptions into three \\ pillars: Channeled Curiosity, Boundary-Breaking Collaboration, and Orchestrated \\ Commercialization. We highlight five principles for achieving Channeled Curiosity: lead with \\ vision, plan strategically, pursue technology platforms, synthesize solutions, and persist. Six \\ principles may help leaders implement Boundary-Breaking Collaboration: lead through \\ persuasion and trust, create interdependence, promote collaboration across disciplines, connect \\ with industry, link universities, and seek active dialogue with government representatives. \\ Finally, just as strategy implementation is notoriously difficult and often poorly executed, \\ commercialization can be a difficult process ${ }^{66}$. We propose six principles to help leaders better \\ Orchestrate Commercialization: coordinate the network, elevate role models, revisit incentives, \\ appoint an industrial liaison officer, improve technology transfer execution, and bring in \\ entrepreneurial and business expertise. By implementing these evidence-based management \\ practices, we suggest that current and future research leaders can orient basic research toward \\ developing ambitious technology platforms that can have practical application, foster
}


collaboration spanning traditional silos, and facilitate a smooth commercialization process that includes all relevant players. Our results show building an organizational culture around these principles can have a dramatic impact on technology transfer outputs. We also propose seven questions for future research to encourage further work in this important area.

\section{Introduction: The innovation imperative}

Innovation is a key battleground in the twenty-first century. Economic experts agree, if any country wants to be a world leader it must successfully innovate, particularly in the science and engineering fields ${ }^{35,56,57}$. A recent study by General Electric found that 95 percent of business executives surveyed across 12 countries agree innovation is critical for a competitive national economy, and 88 percent believe innovation is the best way to create new jobs ${ }^{37}$. The extent to which America relies on innovation is underscored by job distribution; only four percent of the US workforce is comprised of scientists and engineers, but this small minority essentially creates jobs for the other 96 percent $^{57}$.

The United States led in the twentieth century, excelling in endeavors like the atomic bomb, aviation, moon landings, DNA breakthroughs, the personal computer, and the Internet. Suggested reasons for this success include an ambitious immigrant population, effective laws and policies (e.g., effective patent and bankruptcy systems), well-funded corporate research labs, and venture capital availability ${ }^{35,39,65}$. So far in the twenty-first century, American companies and researchers have maintained their lead in many areas, including in new fields like social networking, gene therapy, and big data analytics. But recent statistics warn this lead may be wavering. America has gone from first to fourth among countries known for nurturing innovation ${ }^{30}$. For the first time, the majority of corporations in the 2010 BusinessWeek Top 25 
Most Innovative Companies list were based outside the United States ${ }^{31}$. This may be in part because US companies are investing less in basic research ${ }^{59}$. But US federal government funding of R\&D as a fraction of GDP has also dropped; from 1964 to 2004, it decreased by a startling 60 percent $^{42,60}$. Amid these trends, the US share of global R\&D dropped from 38 to 31 percent between 1999 and 2009 ${ }^{42,59}$. Asian countries had a larger share than the US for the first time in $2009^{59}$. Since 2008, foreign-origin patents have consistently exceeded the number of US-origin patents in the US Patent Office ${ }^{76}$. Perhaps most notably, China increased patent filings by 24 percent in 2012 alone, compared to only 7.8 percent in the US ${ }^{15,83}$.

Clearly, the future of American innovation leadership is not as certain as in the past, and other countries are strong competitors in this innovation race. One potential solution is to increase understanding about the best way to manage innovation. To that end, we offer a theoretical framework, Organized Innovation, which could be used to help leaders better manage innovation efforts. It is based on our decade-long research program on National Science Foundation (NSF) Engineering Research Centers (ERCs) ${ }^{84}$. The ERC Program was launched in 1985 with a mission to strengthen the competitiveness of US firms through improved research and education. The central tenets of the ERC Program include an emphasis on educating future scientists, engineers, and managers of scientists and engineers, interdisciplinary research, academic-industry collaboration, and intentional, aggressive commercialization of research discoveries. See the Appendix for more details on the ERC Program. The Organized Innovation framework is based on extensive qualitative and quantitative research on ERCs.

\section{Contributions}


With this work, we aim to contribute in several ways to engineering management education, and more broadly, the current innovation literature. First, Organized Innovation can be used directly in engineering management education curricula to educate future innovation leaders. The principles in the framework are concrete, yet broad enough to be applied creatively and appropriately across a variety of specific research contexts. They are a set of best practices based on over a decade of research and three decades of ERC success. Thus, we purport they are ready to be disseminated and applied to directly impact engineering management practice today.

Second, the framework extends the extant literature by applying more general innovation and management theory to the specific context of cooperative research centers (CRCs) ${ }^{10}$. CRCs are research organizations comprised of multiple universities and industry partners. They are founded on the premise that collaboration should be institutionalized to enhance innovation potential. To date more than 24,000 CRCs are in the United States and Canada, and more than 13,000 CRCs are in 160 other countries ${ }^{10}$. The ERC Program is one example of a particularly successful CRC program, and was our inspiration in developing this framework. We apply research on motivation, leadership, innovation principles, and technology commercialization to this specific context in efforts to improve outcomes of CRC efforts worldwide, which are heavily tied to management teams of engineering and science researchers. Our research informs their practice directly.

Organized Innovation also contributes to current innovation theory by addressing the challenges associated with complex, large-scale, ambitious research endeavors. By innovation, we focus on disruptive, significant advances and discoveries in technologies, which move from 
initial idea to application in the real world. These large-scale innovation efforts are aimed at generating discontinuous, or disruptive, advances that can radically change the marketplace, the industry, and even develop completely new industries. These research endeavors are notoriously complex; thus, more understanding of the leadership and elements required for successful collaboration and coordination on such a broad scale are desperately needed.

In what follows, we first briefly review the literature on innovation. We then present the Organized Innovation framework and each of its three pillars. In this section we include specific theoretical and empirical evidence of the validity of the framework and specific management prescriptions for teaching and implementing the framework. We also suggest a number of future research questions that would advance the framework, and more generally, the extant literature on innovation management. These research questions are simply meant to provide guidance and ideas for future scholarly efforts.

\section{Landscape of the innovation literature}

Scholars have studied factors predicting successful innovation for several decades. From the many reviews and meta-analyses relating to innovation, we can conclude that the most innovative firms have an external orientation and flexibility to change quickly ${ }^{14}$, that country culture and socioeconomic factors matter for innovation outcomes in firms ${ }^{54}$, and that team processes matter more than team composition or size ${ }^{43}$. Namely, teams with innovationsupportive and excellence-seeking cultures, a clear vision, and broad information-sharing with external entities are more innovative and creative ${ }^{43}$. In all, it seems clear that organizations designed to be more innovative, with these considerations in mind, are likely to be more 
successful. Still, the question remains on precisely how to manage complex innovation efforts. Answering this question has important implications for educating our future innovation leaders, as well as positioning more research entities for successful commercialization outcomes.

In this paper, we focus on what leaders can do to create organizational conditions ripe for innovation success. Thus, we hone in on organizational characteristics and factors leaders control to improve the likelihood of success in the innovation process ${ }^{1,61}$. In the subsequent pages, we provide a brief review of the literature in these areas related most closely to the principles in Organized Innovation. This is not meant to be an exhaustive review, but rather a glimpse into extant knowledge on how to better manage the innovation process.

One of the most popular considerations is collaboration. Collaboration is important because it breeds creativity, increases the relevance of research to solving real-world problems, and increases the capability of a research team to execute, resulting in more successful innovations ${ }^{18,32}$. Experts agree that the US can only be more innovative if we collaborate across scientific, disciplinary, and institutional boundaries ${ }^{21,22}$.

A key aspect of collaboration is dividing the work among universities and industry, and among relevant departments, in which each entity is responsible to a differing degree throughout the commercialization pipeline ${ }^{6,78}$. Open innovation, which includes sharing ideas across organizational boundaries for the purposes of new product development, is one way to achieve division of labor in collaboration ${ }^{17,50}$. Scholars have also suggested that individuals within universities can leverage their unique expertise for leading large-scale research efforts in 
collaboration with industry representatives, whereas individuals within corporations can leverage their vast resources for advancing those discoveries through the commercialization pipeline where they can have an impact on society ${ }^{6,17}$.

Another key consideration for effective collaboration is good communication. Communication should allow participants to consider all relevant ideas and input, and also garner commitment from all participants regarding the overarching vision ${ }^{1,78}$. Communication technology is one important consideration, but basic leadership functions are also critical, including establishing a common language for the team, explicitly setting norms, understanding communication preferences, and translating meaning for all participants. Particularly in research endeavors, leaders must overcome communication challenges that occur when diverse researchers work together on a common project. They must facilitate awareness of each viewpoint and engage in proactive resolution of differences ${ }^{27}$. As these challenges suggest, collaboration can have its drawbacks. Hargadon warns that larger innovation networks mean more time and more relationship management ${ }^{41}$. This conflicts with the need for faster, more efficient idea-to-market innovation processes ${ }^{16}$. Therefore, leaders wanting to increase collaboration should ensure they set proper expectations, use consistent communication and motivation strategies, and enable effective and efficient team-building from the beginning with appropriate team $\operatorname{sizes}^{41,75}$.

Another emergent theme in the recent innovation literature is the paradox between speed to market and long-term execution ${ }^{16}$. Abstract ideas or discoveries must be translated into practice to have any impact, and that translation may take many years ${ }^{20,39,65}$. As Christensen 
says, the development of disruptive innovations often requires a level investment that does not seem to make sense - the pace and prospect of those technologies, by their very nature, must be ahead of their time ${ }^{18}$. This requires risk-taking and forward-thinking from all involved. Leaders often unintentionally undermine research motivation and innovation success when they suffer from strategic attention deficit disorder - an inclination to move to the next big thing before they really know if the current trajectory is working ${ }^{4}$. We suggest that it is possible to aim for efficiency in new product development ${ }^{16}$, while not sacrificing the longer-term focus required for truly disruptive technologies. Some innovation experts have suggested that large-scale institutional collaborations are not needed, and may in fact slow down the process instead of enabling more innovation. Certainly we have seen examples of success in individual or smallerscale innovations (e.g., Apple starting with two guys in a garage). But we propose Organized Innovation as a method for enabling more efficient large-scale innovation in centers like CRCs. This framework may help address the paradox of speed versus long-term execution.

Finally, resource allocation is an important consideration in managing innovation efforts $^{19}$. Although many assume "more is better," research suggests resource utilization (what research teams do with the resources they have) is actually most important ${ }^{77}$. In particular, the team climate for innovation - personal and team capabilities and willingness to take needed risks to overcome barriers - is a significant driver of the success of innovation, even when resources are scarce ${ }^{5,77,79}$. Still, the level of resource allocation by leaders is also a driver of innovation ${ }^{13}$. As Bower and colleagues have suggested, strategy is often decided in a bottom-up fashion, reflected in the ways lower-level managers choose to allocate resources ${ }^{13}$. It is imperative that 
managers at all levels are willing to make resource investments in technologies that develop into the next disruptive discovery, staying true to the strategic goals of the research organization.

As we have shown, several key themes have emerged over the years as scholars have sought to better understand innovation management. In the next section we describe Organized Innovation in detail as an overarching theoretical framework to many of these extant findings. We include specific management prescriptions for teaching and implementing the tenets of the framework to future and current leaders. Finally, we offer future research questions as additional guidance to those interested in studying innovation management.

\section{Overview of Organized Innovation}

Formally defined, Organized Innovation is "a systematic method for leading the translation of scientific discoveries into societal benefits through commercialization” (p. x [from the Preface] $)^{85}$. It is a plan for managing complex innovation efforts, from initial research ideas through commercialization execution. It is meant to be a blueprint for leaders, providing practical guidance about how to manage large innovation efforts. Three pillars comprise the framework: Channeled Curiosity, Boundary-Breaking Collaboration, and Orchestrated Commercialization. As shown in Figure 1, the three pillars of the Organized Innovation framework map onto the phases of the technology commercialization pipeline and call for varying levels of involvement by universities, industry, and government at each phase. This pipeline is consistent with traditional conceptualizations, in which an idea is discovered, disclosed, patented, and then applied through licensure or development within a start-up company ${ }^{46,55,82}$. 


\section{Channeled Curiosity}

The first pillar, Channeled Curiosity, requires "orienting curiosity-driven research toward solving real-world problems for societal benefit" (p. 51) ${ }^{85}$. It is most relevant as leaders guide the first several phases of the commercialization pipeline - from basic research to creation of prototypes. Channeled Curiosity affects these early stages by directing "blue sky" curiositydriven research toward practical application in the form of new products or technologies that can be patented, licensed, and sold by start-up and/or established companies. That is, leaders can help researchers keep the end application of their research efforts in mind, even while pursuing fundamental research that may have many other, yet-unknown applications. Although we are advocates for basic research, within the Channeled Curiosity pillar, we encourage leaders to focus on research inspired by Pasteur's Quadrant, which means routing curiosity toward some identifiable end; one through which people or industries may eventually benefit (Stokes, 1997).

Summarizing what we learned from our extensive data collection of ERCs, we highlight five principles for achieving Channeled Curiosity: lead with vision, plan strategically, pursue technology platforms, synthesize solutions, and persist. First, it is important for leaders to effectively communicate a vision that includes specific, challenging goals. Big challenges can inspire all stakeholders in the research effort and may even attract more research funding ${ }^{65}$. Ambitious visions may originate in a variety of ways - from personal passions, unique interests, or seemingly random curiosities. Whatever the specific projects, decades of goal-setting research supports the idea that leaders should set specific, challenging goals in conjunction with researchers to motivate those researchers to work toward a practical impact. Goals motivate 
individuals because they direct attention and behavior, incite hard work, and encourage persistence until goals are achieved. Specific, challenging goals also encourage people to analyze and apply their own skills and expertise required for goal achievement ${ }^{51}$. Furthermore, when specific, challenging goals are communicated in an inspiring, personalized manner, they are more likely to lead to positive outcomes in terms of team behaviors and perceptions, as these communication strategies motivate and unite people to share appropriate information and work together toward goals ${ }^{26}$.

To facilitate big visions and goal achievement, we recommend a second principle: engage in strategic planning, or the process of setting long-term goals with milestones and action plans ${ }^{66}$. Strategic planning has a proven track record in business (Ramanujan et al., 1986) and the past two decades featured an increase in the use of strategic planning in non-profit and research-based organizations as well ${ }^{47,63}$ (Nutt, 1984; Ring \& Perry, 1985; Steane \& Christie, 2001). Compared to financial metrics, however, less evidence exists on planning in conjunction with innovation outcomes, and strategic planning is not as widely accepted in scholarly settings ${ }^{36}$. This is partially because strategic planning is difficult, particular in uncertain environments like innovation and research. It requires a thorough, big-picture analysis of the relevant landscape, including organizational strengths and weaknesses and external opportunities and threats. Effective planning for large-scale research efforts also requires a broad view of multiple disciplines, commercial markets, and societal dilemmas. This careful analysis may improve definition of the research scope and understanding of the practical implications of the research, as well as increase the likelihood of success. Strategy scholars agree that the process of strategic 
thinking, rather than planning outcomes (i.e., the plan), is often the crucial activity facilitated by strategic planning ${ }^{36,53}$.

As a third recommendation to achieve Channeled Curiosity, we emphasize setting goals focused on development of platforms rather than products. Technology platforms are foundations for multiple products, rather than specific products in and of themselves. Examples include the internal combustion engine, the hypertext transfer protocol, and Apple’s iOS. Products built on those platforms include specific types of cars, specific internet software, and specific Apple products, respectively. As leaders and researchers set goals, we suggest they should pursue projects likely to lead to foundational technologies and the prospect of multiple products and companies, rather than specific products whose potential application may be limited. Our research suggests that focusing on platforms reduces the likelihood and severity of debates over intellectual property rights, and even industry partners who are competitors can come together to support a research center's work because they can each use the platform technology to build their own product implementations. Thus, we posit a platform focus will lead to more impactful and disruptive discoveries that even have the potential to develop entirely new marketplaces and industries. This focus can also lead to healthier relationships between university and industry when it means the technology is early-stage enough to allow for collaboration among competitors.

Beyond platforms, we also suggest a focus on synthesis of solutions, which includes analyzing a problem, breaking it down into appropriate components, borrowing from existing or new technologies, and finally building up a new solution. Synthesis should result in larger, more 
impactful innovation outcomes because it goes beyond component technologies to develop platforms that involve novel tailoring and assembly of discoveries. Indeed, synthesis requires integrating knowledge and capabilities of multiple technologies and systems to create something new. The Wright brothers' advances in flight represent excellent examples of synthesis. They studied different technologies that eventually were put together to create flight. Among other things, they studied aerodynamics using wind tunnel and propeller technology, which led to airplane propellers and wing, and they designed a three-axis control system for steering and maintaining equilibrium in flight. The result was the first controlled, powered flight at Kitty Hawk $^{58}$.

The final principle to achieve Channeled Curiosity is persistence. As Locke and Latham have repeatedly emphasized in their decades of goal-setting research, persistence is critical, and goals help facilitate persistence ${ }^{51}$. Long-term, large-scale, high-impact innovation endeavors will not be simple or quick, but rather will face many intellectual, technical, logistical, emotional, or political challenges along the way. As Hage suggests, time and persistence are the only way we will achieve great breakthroughs ${ }^{39}$. The ERC Program exemplifies this ideal - the typical grant is 10 years, longer than most federal grants.

The intended result of the Channeled Curiosity pillar is to enable basic research to have a greater impact on the real world, thus making a difference in society rather than simply satisfying a researcher's curiosity. In line with that aim, we suggest two directions for future management research on this pillar: motivating researcher behavior toward Channeled Curiosity and assessing the impact of these principles on innovation outcomes. 
First, what motivation strategies are likely to be most effective in encouraging these professionally committed, highly autonomous, highly specialized knowledge workers to focus on end-result impacts rather than purely curiosity-driven research? Based on the motivation and leadership literatures ${ }^{34}$, empowerment is a potentially good strategy when tasks are ambiguous and employees are highly skilled. But this is likely a default method of leadership in this context, and leaders we interviewed in our research expressed a desire to know more about how to motivate. Thus, research exploring more specific leadership behaviors as they attempt to communicate a compelling vision that persuades researchers to consider this longer-term focus would be useful. Furthermore, research should consider how to motivate researchers to participate meaningfully in a strategic planning process, to help define platform-oriented goals that require broad synthesis rather than smaller scale innovation. Finally, we must better understand what specific leadership strategies may keep researchers and external stakeholders engaged and focused over a long time period. Thus, we offer our first research question:

Research Question 1. What are the most effective methods for motivating researchers to pursue research with impactful societal applications?

Second, specific outcomes should be explored to test the value of the Channeled Curiosity principles in relation to desirable outcomes of innovation. That is, research that investigates the outcomes of basic research conducted with a Channeled Curiosity focus, versus with a traditional focus on pure curiosity, would be valuable. Outcomes might include simple counts of invention disclosures, patents, and licenses, or more downstream impacts, such as 
product success, job creation, spin-off companies, or other indicators of quality of life enhancements. As Feller, Ailes, and Roessner lamented, it is notoriously difficult to capture the full extent of innovation impact, but a mix of measures is likely the best approach ${ }^{33}$. Thus, we offer our third and final question for Channeled Curiosity:

Research Question 2. What impact does Channeled Curiosity have on innovation outcomes, including invention disclosures, patents, licenses, job created, new product success, and spin-off companies founded?

In addition to these two questions, each principle of Channeled Curiosity suggests a plethora of research directions. For instance, how can leaders engage in effective strategic planning in a research setting, what is the ideal timeframe for "persistence," and how do leaders best put together the talents required for solution synthesis? We are confident that scholars interested in this area can generate even more elaborate research agendas than those suggested here.

\section{Boundary-Breaking Collaboration}

Consistent with extant innovation literature, which places strong emphasis on effective collaboration, Boundary-Breaking Collaboration represents the facilitation of "information flow and collaboration among individuals representing different disciplines and perspectives in an effort to make new research discoveries more innovative” (pp. 51-52) ${ }^{85}$. Principles inherent in this pillar are critical throughout all phases of the commercialization pipeline. In the early phases, proper collaboration can help inform research goals and solve complex problems through 
multidisciplinary and industry-university information-sharing. It is also critical as enabling component technologies move toward proofs-of-concepts, commercial prototypes, and generation of spin-offs and new marketable products. This is the transition in which many technologies fall into the "innovation gap" because no one is willing to invest in them when they are still high-risk and early-stage. Strong collaboration across disciplines and institutions can help close this gap and scale more technologies to the point where they can be sold in the marketplace $e^{38}$.

Throughout these phases, leaders act as facilitators to help researchers work across traditional boundaries, including those separating disciplines and institutions, in efforts to produce more high-potential innovations. As described earlier, the need for collaboration in innovation efforts is widely recognized. Indeed, research shows that collaborative team efforts produce more citations for publications, more patents, and more breakthrough discoveries in general $^{48}$. Meta-analytic research shows that teams that cross boundaries in their communications are more innovative and creative ${ }^{43}$. In the business sector, more profits may result, as suggested by a study of 2,500 IBM employees; each email contact totaled $\$ 948$ more revenue, on average ${ }^{7}$. Research on ERCs also supports these trends. Namely, patent awards were thirty times more likely to occur in an ERC where participants "Strongly Agreed” their climate was characterized by boundary spanning as compared with a climate where participants merely “Agreed” their climate was boundary spanning ${ }^{44}$.

One reason for collaboration is the growing complexity of knowledge and increased specialization as a result; collaboration occurring across key boundaries improves the likelihood 
that a problem can be defined and solved comprehensively and creatively ${ }^{2,62}$. This boundarycrossing collaboration generates new ideas by leveraging diverse perspectives, knowledge, and skills $^{3}$. It may also secure more resources throughout the research process, such as lab space to create prototypes, which can enhance commercialization potential of a discovery.

Despite its importance and its proliferation, collaboration is not easy. Based on our research on ERCs, we emphasize six principles that may help leaders implement effective, broad-based collaboration. The first two principles focus on management processes for enhancing the effectiveness of collaboration. The last four represent boundaries that should be crossed. The six principles are: lead through persuasion and trust, create interdependence, promote collaboration across academic disciplines, connect with industry, link universities, and seek active dialogue with government representatives.

First, our research on ERCs suggests that leaders must persuade stakeholders that they can and should engage in cross-boundary collaboration on the basis that all can be trusted to fulfill their obligations in the relationship. Leaders increasingly rely on decentralized management strategies when projects are dispersed and organizational structures are flat; this is in line with popular leadership theories that cite task-focused empowerment when tasks are ambiguous and uncertain ${ }^{9,34}$. In this effort, leaders need skills to persuade stakeholders to collaborate with others, particularly those with whom they might not otherwise work. Leaders must also inspire trust among all involved, as trust encourages people to voluntarily share information and ideas more efficiently ${ }^{19,23,24,25,29}$. 
The second principle of Boundary-Breaking Collaboration emphasizes designing research to require cross-boundary interdependence. Designing projects so that individual researchers and even research teams must depend on others throughout the process may enhance the frequency, efficiency, and effectiveness of interactions. In general, individuals who cross boundaries to collaborate with more diverse individuals are more likely to hear and incorporate diverse viewpoints in the research, leading to more comprehensive and innovative research trajectories. But diverse individuals often do not seek out opportunities to collaborate if it seems possible to accomplish tasks without doing so.

Therefore, it is important to require interactions among the diverse players. Such requirements have a secondary benefit beyond producing more innovative discoveries. The costs associated with establishing these interdependent relationships may encourage more commercialization to help justify the investments made in building the cross-boundary team ${ }^{48}$. Key in this institutionalization of collaboration is an emphasis on helping stakeholders establish and strengthen working relationships so they are not hindered by their interdependence, but rather reap its benefits.

The third principle emphasizes interdisciplinary collaboration. Collaboration across academic boundaries helps research teams tackle more complex, audacious problems because more knowledge and skills can be incorporated. Kotha et al. argue that more commercialization occurs when scholars from more distant academic disciplines work together ${ }^{48}$. That is, fields that are very different are more likely to define a complex, important problem and find innovative ways to solve it than closely related fields. The more diverse participants are, however, the more 
disagreements are likely to occur. But research has shown that leaders who facilitate open discussion of disagreements and provide task-oriented support are the most effective in facilitating interdisciplinary research endeavors.

Fourth, individuals should cross the industry-university boundary, which has been shown to generate more patents, licenses, and spin-off firm success ${ }^{69,72,73,74}$. This is likely because research becomes more relevant for application in the "real world" when industry perspectives are considered, including input on market demand and needed solutions ${ }^{73,84}$. Industry relationships may also enable discoveries to be applied more readily than when university researchers work in isolation from industry. Although companies in emerging industries may be more likely to collaborate with universities for research and development than in mature industries $^{11}$, we saw firms in both types of industries benefit from ERC collaboration. Finally, our research also supports extant recommendations to improve industry-university ties maintaining a focus on building stakeholder commitment, in part through a designated liaison responsible for relationship management ${ }^{80}$.

The fifth principle of Boundary-Breaking Collaboration encourages individuals to cross university boundaries. This can result in new, productive collaborations among scholars who possess complementary expertise, as well as increased access to resources such as equipment, research participants, and funding. Indeed, multi-university research teams are the fastest growing type of research collaboration ${ }^{40,45}$. An exemplar of this form of collaboration is the Wallace H. Coulter Department of Biomedical Engineering, a joint department founded through partnership involving Georgia Tech and Emory University. In 2012, U.S. News \& World Report 
ranked the department's undergraduate and graduate programs second in the nation in biomedical engineering.

Finally, research leaders who purposely cultivate relationships between universities and government entities may realize more innovation success. Partnerships with government officials responsible for writing funding solicitations may inform the direction of solicitations and increase chances of winning the funding. University and industry leaders can alert government officials of the most pressing needs for research, beyond selfish political lobbying. Research leaders can also benefit from fostering a university-government coaching relationship. This approach can tap into the government officials' vast knowledge of best practices, since they typically manage large portfolios of research investments, and they can see what works and does not work. In addition, a nonthreatening, coaching approach by government officials may help ensure more success from investments by fostering better information sharing and increasing chances of receiving government research funding. Such government representatives might also be more inclined to facilitate collaboration among leaders of similar research centers to share best practices and lessons learned.

Extending the principles included in the pillar of Boundary-Breaking Collaboration, we first suggest additional research on communication. Namely, we suggest scholars explore specific strategies leaders might use to communicate with people from different disciplines, backgrounds, and incentive structures (e.g., academics, industry, and government). Findings from general communication and team research could be applied to this specific collaborative 
context to provide recommendations for those engaged in innovation. Thus, our third research question:

Research Question 3. What specific strategies are most useful to facilitate effective communication between academic researchers, industry partners, and government officials?

Much of the general knowledge from the management literature can be applied to help improve collaboration processes, but the research endeavors we discuss in this pillar are larger and more complex than typical workgroups. Teams formed from multiple universities, multiple academic disciplines, along with private-sector companies, may require a specific set of leader behaviors to facilitate high-performance outputs. Therefore, empirical examination of leader behaviors in facilitating these relationships would be valuable.

Research Question 4. What specific leadership behaviors are most effective in facilitating successful collaboration relationships across each unique boundary?

As with the first pillar, more specific research questions could also be addressed for each of the six principles in this pillar. For example, what strategies can leaders in innovation contexts use to foster trust among collaborating stakeholders, and what types of task interdependencies are best used to require more collaboration? Furthermore, what specific strategies can be used to address boundary-specific challenges, such as the pace and language differences between university and industry, or the power distance and status differences that may be perceived between government and university officials? 


\section{Orchestrated Commercialization}

The third and final pillar, Orchestrated Commercialization, requires “intentionally coordinating complementary players_-researchers, patent officers, entrepreneurs, financial investors, and corporations - to maximize the success of the technology commercialization

process” (p. 52) ${ }^{85}$. The tenets of this pillar are particularly vital in the middle and latter stages of the commercialization pipeline, as they help bring technologies from proofs-of-concept to commercial prototypes and beyond. Our research on ERCs suggested that leaders must act as inspiring brokers to motivate and support all parties as they fulfill their particular roles in the commercialization process. This goes beyond the research process into the specific steps required to bring a new discovery to market. The brokering work required to orchestrate the commercialization effort is much like matchmaking - recruiting and coordinating the talents of diverse but complementary players, and forging productive connections among them. Thus, leaders need to understand and navigate diverse disciplines, laws, policies, and entrepreneurship practices in their efforts to translate research into products and services that can have a realworld impact.

Prioritization on commercialization execution answers calls made by a 2012 study from the President's Council of Advisors on Science and Technology (PCAST) ${ }^{64}$. From this study, PCAST recommended that universities should act as “central engines of innovation and geographical anchors of the Nation’s science and technology enterprise” (PCAST, 2012). The PCAST report also noted that American research universities have made great strides in this area and "are closer to the marketplace than they have ever been, with a focus on translating and 
transferring research discoveries to industry” (p. 100) ${ }^{85}$. ERCs are one exemplar of this movement.

The ERC Program has had unusual success bringing research discoveries to the market in a variety of industries. For example, at one ERC based at Caltech, the Center for Neuromorphic Systems Engineering (CNSE), a SRI International study concluded this center's total impact on the American economy was about \$173 million. This represents nearly a sevenfold return on investment from their original funding of about $\$ 25$ million $^{67}$. However, not all ERCs were equally successful and one important differentiator of whether ERCs achieved strong commercialization output was cultivating a climate within the ERC that supported and promoted commercialization. For example, research demonstrates that invention disclosures were four times more likely in an ERC where participants “Strongly Agreed” that their climate supported commercialization compared with an ERC where participants merely “Agreed” that their climate supported commercialization ${ }^{44}$. By focusing on commercialization support, leaders provide resources and incentives to encourage researchers to take time away from research and other obligations to formally file an invention disclosure. This support is found in a climate for innovation, where new idea generation is supported ${ }^{5}$; commercialization support climate extends the focus to later stages of the commercialization pipeline.

Just as strategy implementation is notoriously difficult and often poorly executed, commercialization can be a complex difficult process ${ }^{66}$. Our study of ERCs suggests six principles to help leaders better orchestrate commercialization: coordinate the network, elevate role models, revisit incentives for commercializing academic research, appoint an industrial 
liaison officer, improve technology transfer and administrative execution, and bring in entrepreneurial and business expertise.

First, coordinating the network involves one of the most important activities in Orchestrated Commercialization. This is essentially the matchmaking component, which assembles all required players. For example, researchers, officials in technology transfer offices, entrepreneurs, and lawyers may all be required to bring the technology to the market. If a proof of concept is not yet built, skilled technicians or engineers, from industry or another academic institution, may be required. Leaders may also need to work with venture capitalists or larger corporations to acquire resources to allow the technology to progress toward a marketable product. Matthew Wood highlighted the need to make these connections carefully, ensuring that the technology needs are carefully matched to appropriate partners ${ }^{81}$. Leaders are the master orchestrators of all these relationships, and they can help facilitate the networking required to bring technology breakthroughs to where they can impact society ${ }^{28,41}$. In this coordination effort, leaders must communicate an inspiring vision to motivate each player to contribute and work together in the commercialization process. This requires a special understanding of each player, including what motivates them and what benefits they expect to receive from their participation in the process.

The second principle is elevating role models. Role modeling is a powerful motivator for changing behavior because it shows people what is possible and how to actually achieve desired outcomes $^{8}$. Role models themselves may also provide networks, encouragement, and advice for others wishing to follow their example ${ }^{12}$. Therefore, finding and broadcasting innovation-related 
achievements of peers may encourage more researchers to overcome any barriers or hassles associated with participating in the commercialization process. Even communication about small commercialization successes can motivate other scholars to pursue similar goals as they see what is possible.

The third principle is to establish an effective incentive system consistent with the aims of commercialization. Research shows that 30 percent of researchers are not involved at all in the commercialization of a technology they invented ${ }^{82}$. Incentivizing involvement in this process may help accelerate the commercialization of technologies ${ }^{65,82}$. To achieve researcher participation in commercialization, it may be necessary to broaden the traditional academic criteria used in annual performance reviews and tenure and promotion decisions beyond conventional publication-focused measures. Criteria may include specific milestones achieved through interdisciplinary work on longer-term projects that are moving toward commercialization. Leaders could also use smaller, more local rewards to incentivize researchers, such as one-time stipends, endowed professorships, or even seed funds to motivate more relevant research that can be moved toward commercialization.

The fourth principle calls for leaders to establish a formal position within the research organization responsible solely for managing the university-industry interface. In ERCs, this person is referred to as the industrial liaison officer (ILO). The scope of this position includes fostering industry relationships and understanding industry needs, which can then help inform research directions. They should also act as a liaison for commercialization activities by interfacing with technology transfer professionals, enabling an easier commercialization process 
for researchers. Finally, they should even more broadly support commercialization efforts through training, relationship-forging, and success communication. Research shows that a liaison can help improve relationships between involved $\operatorname{parties}^{80}$, and we suggest giving universityindustry liaisons responsibility throughout the commercialization process. In our research, we found that the most successful ILOs served both as "evangelists of the value of technology commercialization and as providers of resources to researchers, the tech transfer office, and industry to coordinate effective collaboration among all participants” (p. 104) ${ }^{85}$.

As a fifth principle for achieving Orchestrated Commercialization, we note the need to improve the administrative aspect of technology transfer execution. Innovation experts often lament the lack of commercialization activity in many American universities, and administrative execution is partly to blame. TTOs with a customer-service focus make the commercialization process more pleasant for all involved ${ }^{68}$. Beyond attitudes, TTOs who have sufficient resources and well-organized procedures that facilitate researcher involvement in an efficient way are typically more efficient in attaining commercialization success. And in turn, TTOs that focus on speed to market rather than maximizing financial gains are more successful in the long run, including in licensing revenues and fostering long-term industry partnerships ${ }^{52}$. MIT provides an example of this approach. That TTO focuses on speedy execution through the commercialization process, which enhances long-term relationships with industry, more licensing revenue, and more inventions overall out to the real world (Roberts, 2012). Administrative support staff within the research center can also be a tremendous help to researchers and leaders who need to maintain focus on research rather than administrative activities, such as patent filings, involved in commercialization. 
Our sixth and final recommendation calls on leaders to forge relationships with entrepreneurs and those involved in the business schools at their corresponding universities. These include venture capitalists, business development officials, and local entrepreneurs, but also professors and advanced students in business and professional schools across the university. Students can potentially serve as employees or managers in new firms, or provide earlier-stage help, such as market research, feedback on prototypes, and business plan development. Advocacy groups, university alumni groups, and local business incubators may also be valuable to research centers looking to improve their commercialization success rate. These groups can offer valuable advice, start-up resources, and networking opportunities to advance the success of the technology being commercialized. For example, the Center for Biological and Environmental Nanotechnology (CBEN) at Rice University forged close ties with the Rice Alliance for Technology and Entrepreneurship, which helped launch Carbon Nanotechnologies and several other start-ups out of CBEN's research activities. The Rice Alliance is a partnership among the university’s engineering, natural sciences, and business schools. The Alliance helped CBEN by pulling in entrepreneurs, investors, and businesspeople who were both alumni and non-alumni.

Much research has been conducted on the commercialization process, but we suggest too little attention has been paid to the leadership behaviors and skills and the institutional factors in large-scale innovation efforts that improve the success and satisfaction of the commercialization process for all involved. We see several key avenues of further study. First, leaders in multiinstitutional research centers can do much to facilitate the commercialization process more effectively and efficiently. For example, how they communicate with everyone involved, how 
involved the leaders themselves stay in the process, and who they specifically engage at various phases are all aspects of leadership behavior that may affect the process. Thus, as a first avenue for future research, we suggest investigations of specific leadership behaviors that facilitate the commercialization process.

Research Question 5. Which leadership behaviors are most strongly related to commercialization success and satisfaction for all involved?

It will also be useful to understand more about the leadership skills required to effectively implement Orchestrated Commercialization. For example, what communication, project management, and entrepreneurial skills are required to coordinate all the processes necessary to bring technology breakthroughs through the commercialization process? What leadership skills can be cultivated to help leaders forge and maintain the necessary relationships to improve technology commercialization execution? What training might leaders offer researchers to maximize their involvement and the subsequent success of the process? In exploring these themes, scholars might assess leadership or mentorship programs that can help current and future leaders prepare for the audacious task of leading large-scale innovation efforts based on Organized Innovation principles.

Research Question 6. What specific leadership skills are necessary to orchestrate commercialization and how can those skills be best developed? 
Finally, as previous research has shown, institutions that can fully support the commercialization process are most likely to be successful. Thus, research on specific factors, such as TTO climate and processes, boundary-role liaisons formally appointed in the various participating entities, and cultural norms supporting commercialization are all good targets of research. Furthermore, organizational climate change is a significant undertaking, so obstacles and solutions to implementing relevant policies and procedures might also be valuable to explore in this innovation-pursuit context. Incentive systems (both financial and nonfinancial) are one such institutional change that can be tweaked to increase innovation activity by researchers in various phases of the pipeline.

Research Question 7. What impact do institutional factors have on commercialization success and satisfaction?

Many other specific questions might be raised for each of the six principles supporting this pillar. For instance, developing metrics for the level of each principle would be valuable, just as with the other pillars. Furthermore, more research on specific incentive strategies would be valuable. And understanding more about the required competencies for boundary-spanning roles, such as ILOs and people working in TTOs would be useful. By pursuing research on this particular pillar of Organized Innovation, we can take an important step toward better understanding how research discoveries can successfully traverse the entire commercialization pipeline, rather than get stuck in an early stage.

\section{Application to engineering management education}


We see tangible value of the Organized Innovation framework for the broad spectrum of engineering management education. For those who are preparing for research and development leadership roles, the principles clearly apply. But even for those who are managing other engineers not involved in research and development, we believe the principles can help them lead more effectively, particularly as they facilitate widespread collaboration among many technical minds. Thus, faculty who integrate these principles in their curriculum will better prepare students to excel in whatever their chosen path may be.

\section{Conclusion}

The Organized Innovation framework represents a plan to improve the research enterprise. The framework is based on best practices uncovered in our and other scholars' research on ERCs and similar research center programs. It is also consistent with well-supported theories of innovation, collaboration, motivation, and management in general. It includes theoretically- and empirically-supported principles that may be further applied and validated by researchers and implemented by leaders of innovation efforts. Thus, these principles may be integrated within engineering management curricula, in addition to current engineering management practice - providing value for current and future research leaders. We encourage additional efforts to test these principles across the diverse range of research centers focused on large-scale innovation, as well as additional related research, as suggested in the seven research questions in this paper. We believe research in this area can act as a foundation for an innovation enterprise that can position America and other global leaders to compete more successfully in this critical twenty-first century battleground. 


\section{BIBLIOGRAPHY}

1. Aasen, T., \& Johannessen, S. 2009. Managing innovation as communicative processes: A case of subsea technology R\&D. International Journal of Business Science \& Applied Management, 4: 22-33.

2. Adams, J. S. 1976. The structure and dynamics of behavior in organizational boundary roles. In M. D. Dunnette and L. M. Hough (Eds.), Handbook of Industrial and Organizational Psychology (pp. 1175-1199). Palo Alto, CA: Consulting Psychologists Press.

3. Aldrich, H. E., \& Herker, D. 1977. Boundary spanning roles and organization structure. Academy of Management Review, 2: 217-230.

4. Amabile, T. M., \& Khaire, M. 2008. Creativity and the role of the leader. Harvard Business Review, 10: 100109.

5. Anderson, N., Hardy, G., \& West, M. 1990. Innovative teams at work. Personnel Management, 22: 48-53.

6. Anthony, S. D. 2012. The new corporate garage. Harvard Business Review, 90: 44-53.

7. Baker, S. 2009, April 8. Putting a price on social connections. Bloomberg Businessweek. Retrieved 5/3/2013 from http://www.businessweek.com/stories/2009-04-08/putting-aprice-on-social-connectionsbusinessweekbusiness-news-stock-market-andfinancial-advice.

8. Bercovitz, J., \& Feldman, M. 2008. Academic entrepreneurs: Organizational change at the individual level. Organization Science, 19: 69-89.

9. Birnbaum, P. H. 1979. A theory of academic interdisciplinary research performance: A contingency and path analysis approach. Management Science, 25: 231-242.

10. Boardman, C., \& Gray, D. 2010. The new science and engineering management: Cooperative Research Centers as government policies, industry strategies and organizations. Journal of Technology Transfer, 35: 445-459.

11. Bodas Freitas, I., Marques, R., \& Silva, E. 2013. University-industry collaboration and innovation in emergent and mature industries in new industrialized countries. Research Policy, 42: 443-453.

12. Bosma, N., Hessels, J., Schutjens, V., Praag, M., \& Verheul, I. 2012. Entrepreneurship and role models. Journal of Economic Psychology, 33: 410-424.

13. Bower, J. L., \& Gilbert, C. G. 2007. How managers' everyday decisions create or destroy your company's strategy. Harvard Business Review, 85: 72-79. 
14. Büschgens, T., Bausch, A., \& Balkin, D. B. 2013. Organizational culture and innovation: A meta-analytic review organizational culture and innovation: a meta-analytic review. Journal of Product Innovation Management, 30: 763-781.

15. Casey, J., \& Koleski, K. 2011. Backgrounder: China's 12th Five-Year Plan. Washington, DC: U.S.-China Economic and Security Review Commission. Retrieved 12/15/2012 from http://origin.www.uscc.gov/sites/default/files/Research/12th-FiveYear-Plan_062811.pdf.

16. Chen, J., Damanpour, F., \& Reilly, R. R. 2010. Understanding antecedents of new product development speed: A meta-analysis. Journal of Operations Management, 28: 17-33.

17. Chesbrough, H. 2006. Open business models: How to thrive in the new innovation landscape. Boston, MA: Harvard Business Review Press.

18. Christensen, C. M. 1997. The innovator's dilemma: When new technologies cause great firms to fail. Boston, MA: Harvard Business School Press.

19. Clegg, C., Unsworth, K., Epitropaki, O., \& Parker, G. 2002. Implicating trust in the innovation process. Journal of Occupational and Organizational Psychology, 75: 409-422.

20. Collins, J., \& Hansen, M. T. 2011. Great by choice: Uncertainty, chaos, and luck-why some thrive despite them all. New York, NY: HarperBusiness.

21. Committee on a New Biology for the 21st Century. 2009. A New Biology for the 21st Century. Washington, DC: National Academies Press. Retrieved 12/30/2013 from http://www.nap.edu/openbook.php?record_id=12764\&page=1.

22. Committee on Research Universities, Board on Higher Education and Workforce, Policy and Global Affairs, and National Research Council. 2012. Research Universities and the Future of America: Ten Breakthrough Actions Vital to our Nation's Prosperity and Security. Washington, DC: National Academies Press.

23. Currall, S. C., \& Epstein, M. J. 2003. The fragility of organizational trust: Lessons from the rise and fall of Enron. Organizational Dynamics, 32: 193 - 206.

24. Currall, S. C., \& Inkpen, A. C. 2006. On the complexity of organizational trust: A multi-level coevolutionary perspective and guidelines for future research. In R. Bachmann and A. Zaheer (Eds.) The Handbook of Trust Research (pp. 235-46). Cheltenham, UK: Edward Elgar. 
25. Currall, S. C., \& Judge, T. A. 1995. Measuring trust between organizational boundary role persons. Organizational Behavior and Human Decision Processes, 64: 151-170.

26. De Vries, R. E., Bakker-Pieper, A., \& Oostenveld, W. 2010. Leadership = communication? The relations of leaders’ communication styles with leadership styles, knowledge sharing and leadership outcomes. Journal of Business \& Psychology, 25: 367-380.

27. Dibble, R., \& Gibson, C. 2013. Collaboration for the common good: An examination of challenges and adjustment processes in multicultural collaborations. Journal of Organizational Behavior, 34: 764-790.

28. Dyer, J. H., Gregersen, H. B., \& Christensen, C. M. 2009. The Innovator's DNA. Harvard Business Review, 87: 60-67.

29. Dyer, J. H., \& Wujin, C. 2003. The role of trustworthiness in reducing transaction costs and improving performance: Empirical evidence from the United States, Japan, and Korea. Organization Science, 14: 57-68.

30. Economist. 2013, March 16. Special report: America's competitiveness. Retrieved 12/30/2013 from http://www.economist.com/blogs/democracyinamerica/2013/03/special-report-americas-competitiveness.

31. Einhorn, B., \& Arndt, M. 2010, April 15. The 25 most innovative companies 2010. Bloomberg Businessweek. Retrieved 12/30/2013 from http://images.businessweek.com/ss/10/04/0415_most_innovative_companies/index.htm?chan=magazine+cha nnel_special+report.

32. Eschenbaecher, J., \& Graser, F. 2011. Managing and optimizing innovation processes in collaborative and value creating networks. International Journal of Innovation \& Technology Management, 8: 373-391.

33. Feller, I., Ailes, C. P., \& Roessner, J. D. 2002. Impacts of research universities on technological innovation in industry: Evidence from Engineering Research Centers. Research Policy, 31: 457-474.

34. Fiedler, F. E. (1965). The contingency model: A theory of leadership effectiveness. In H. Proshansky and B. Seidenberg (Eds.), Basic studies in social psychology (pp. 538-551). New York City, NY: Holt, Rinehart, and Winston.

35. Friedman, T. L., \& Mandelbaum, M. 2011. That used to be us: How America fell behind in the world it invented and how we can come back. New York, NY: Farrar, Straus and Giroux.

36. Galloway, I. D. 1990. Strategic management in public sector research organisations: A critical review. International Journal of Public Sector Management, 3: 5-24. 
37. General Electric. 2011. GE Global Innovation Barometer 2011: An Overview on Messaging, Data and Amplification. Retrieived September 5, 2012 from http://files.gereports.com/wpcontent/uploads/2011/01/GIB-results.pdf.

38. Grove, A. 2010, July 1. How America can create jobs. Bloomberg Businessweek. Retrieved 12/30/2013 from http://www.businessweek.com/magazine/content/10_28/b4186048358596.htm.

39. Hage, J. 2011. Restoring the Innovative Edge: Driving the Evolution of Science and Technology. Palo Alto, CA: Stanford University Press.

40. Hale, K. 2012, August. Collaboration in academic R\&D: A decade of growth in pass-through funding.” InfoBrief (National Center for Science Engineering Statistics/National Science Foundation). Retrieved 1/23/2013 from http://www.nsf.gov/statistics/infbrief/nsf12325/\#note2.

41. Hargadon, A. 2003. How breakthroughs happen: The surprising truth about how companies innovate. Boston, MA: Harvard Business School Press.

42. Hourihan, M. 2013. Historical Trends in Federal R\&D. AAAS Report XXXVII Research and Development FY 2013. Washington, DC: American Association for the Advancement of Science. Retrieved 12/30/2013 from http://www.aaas.org/sites/default/files/migrate/uploads/14pch02.pdf.

43. Hülsheger, U. R., Anderson, N., \& Salgado, J. F. 2009. Team-level predictors of innovation at work: A comprehensive meta-analysis spanning three decades of research. Journal of Applied Psychology, 94: 11281145.

44. Hunter, E. M., Perry, S. J., \& Currall, S. C. 2011. Inside multi-disciplinary science and engineering research centers: The impact of organizational climate on invention disclosures and patents. Research Policy, 40: 1226-1239.

45. Jones, B.F., Wuchty, S., Uzzi, B. 2008. Multi-university research teams: Shifting impact, geography, and stratification in science. Science, 322: 1259-1262.

46. Khilji, S. E., Mroczkowski, T., \& Bernstein, B. 2006. From Invention to innovation: Toward developing an integrated innovation model for biotech firms. Journal of Product Innovation Management, 23: 528-540.

47. Kong, E. 2008. The development of strategic management in the non-profit context: Intellectual capital in social service non-profit organizations. International Journal of Management Reviews, 10: 281-299. 
48. Kotha, R., George, G., \& Srikanth, K. 2013. Bridging the mutual knowledge gap: Coordination and the commercialization of university science. Academy of Management Journal, 56: 498-524.

49. Lewis, C. S. 2010. Engineering research centers: Innovations-ERC-generated commercialized products, processes, and startups. Arlington, VA: National Science Foundation. Retrieved 3/20/2013 from http://www.erc-assoc.org/topics/policies_studies/ERC\%20Innovations\%202010-final.pdf.

50. Lichtenthaler, U. 2011. Open innovation: Past research, current debates, and future directions. Academy of Management Perspectives, 25: 75-93.

51. Locke, E. A., \& Latham, G. P. 2002. Building a practically useful theory of goal setting and task motivation. American Psychologist, 57: 705-717.

52. Markman, G. D., Gianiodis, P. T., Phan, P. H., \& Balkin, D. B. 2005. Innovation speed: Transferring university technology to market. Research Policy, 34: 1058-1075.

53. Mintzberg, H. 1994. The rise and fall of strategic planning. New York City: The Free Press.

54. Mueller, V., Rosenbusch, N., \& Bausch, A. 2013. Success patterns of exploratory and exploitative innovation: A meta-analysis of the influence of institutional factors. Journal of Management, 39: 16061636.

55. Myers, D. R., Sumpter, C. W., Walsh, S. T., \& Kirchhoff, B. A. 2002, November. A practitioner's view: Evolutionary stages of disruptive technologies. IEEE Transactions on Engineering Management: 322.

56. National Academies. 2007. Rising above the Gathering Storm: Energizing and Employing America for a Brighter Economic Future. Washington, DC: National Academies Press.

57. National Academies. 2010. Rising above the Gathering Storm, Revisited: Rapidly Approaching Category 5. Washington, DC: National Academies Press.

58. National Aeronautics and Space Administration. 2010. Reliving the Wright way. Retrieved 12/30/2013 from http://wright.nasa.gov/index.htm.

59. National Science Board. 2012. Science and engineering indicators 2012. Arlington, VA: National Science Foundation. Retrieved 12/5/2012 from http://www.nsf.gov/statistics/seind12.

60. National Science Foundation. 2010. National patterns of R\&D resources: 2008 data update, NSF 10-314. Arlington, VA: National Science Foundation. Retrieved 12/5/2012 from http://www.nsf.gov/statistics/nsf10314/. 
61. O’Shea, R. P., Chugh, H., \& Allen, T. J. 2008. Determinants and consequences of university spinoff activity: A conceptual framework. Journal of Technology Transfer, 33: 653-666.

62. Owen-Smith, J., \& Powell, W. W. 2003. The expanding role of university patenting in the life sciences: Assessing the importance of experience and connectivity.” Research Policy, 32: 1695-1711.

63. Pereira, P. L., \& Veloso, F. M. 2009. R\&D activity selection process: Building a strategy-aligned R\&D portfolio for government and nonprofit organizations. IEEE Transactions on Engineering Management, 56: 95-105.

64. President's Council of Advisors on Science and Technology (PCAST). Transformation and Opportunity: The Future of the U.S. Research Enterprise. Washington, DC: President's Council of Advisors on Science and Technology, 2012. Retrieved 5/5/2013 from http://www.whitehouse.gov/sites/default/files/microsites/ostp/pcast_future_research_enterprise_20121130.pd f.

65. Quinn, J. 1985. Managing innovation: Controlled chaos. Harvard Business Review, 63: 73-84.

66. Ramanujam, V., Venkatraman, N., \& Camillus, J. C. 1986. Multi-objective assessment of effectiveness of strategic planning: A discriminant analysis approach. Academy of Management Journal, 29: 347-72.

67. Roessner, D., Manrique, L., \& Park, J. 2010. The economic impact of Engineering Research Centers: Preliminary results of a pilot study. Journal of Technology Transfer, 35: 475-493.

68. Schneider, B., White, S. S., \& Paul, M. C. 1998. Linking service climate and customer perceptions of service quality: Test of a causal model. Journal of Applied Psychology, 83: 150-164.

69. Shane, S., \& Stuart, T. E. 2002. Organizational endowments and the performance of university start-ups. Management Science, 48: 154-170.

70. Steane, P. D., \& Christie, M. 2001. Nonprofit boards in Australia: A distinctive governance approach. Corporate Governance: An International Review, 9: 48-58.

71. Stokes, D. E. 1997. Pasteur's Quadrant: Basic science and technological innovation. Washington, DC: Brookings Institution Press.

72. Stuart, T. E. 2000. Interorganizational alliances and the performance of firms: A study of growth and innovation rates in a high-technology industry.” Strategic Management Journal, 21: 791-811. 
73. Stuart, T. E., \& Ding, W. W. 2006. When do scientists become entrepreneurs? The social structural antecedents of commercial activity in the academic life sciences. American Journal of Sociology, 112: 97144.

74. Thursby, J. G., \& Thursby, M. C. 2004. Are faculty critical? Their role in university-industry licensing. Contemporary Economic Policy, 22: 162-178.

75. Tuckman, B. W. 1965. Developmental sequence in small groups. Psychological Bulletin, 63: $384-399$.

76. US Patent and Trademark Office. 2012. Patents by country, state, and year-utility patents. Retrieved April 24, 2013 from http://www.uspto.gov/web/offices/ac/ido/oeip/taf/cst_utl.htm.

77. Weiss, M., Hoegl, M., \& Gibbert, M. 2013. The influence of material resources on innovation projects: the role of resource elasticity. $\boldsymbol{R} \& \boldsymbol{D}$ Management, 43: 151-161.

78. Wells, R. J. 2008. The product innovation process: Are managing information flows and cross-functional collaboration key? Academy of Management Perspectives, 22: 58-60.

79. West, M. A. 1990. The social psychology of innovation in groups. In West, M.A. and Farr, J.L. (Eds), Innovation and Creativity at Work: Psychological and Organizational Strategies (pp. 309-333). Chichester, UK: Wiley.

80. Wohlin, C., Aurum, A., Angelis, L., Phillips, L., Dittrich, Y., Gorschek, T., \& Winter, J. 2012. The success factors powering industry-academia collaboration. IEEE Software, 29: 67-73.

81. Wood, M. S. 2009. Does one size fit all? The multiple organizational forms leading to successful academic entrepreneurship. Entrepreneurship Theory and Practice, 33: 929-947.

82. Wood, M. S. 2011. A process model of academic entrepreneurship. Business Horizons, 54: $153-161$.

83. World Intellectual Property Organization. 2013. World intellectual property indicators-2013 edition. Geneva, Switzerland: World Intellectual Property Organization. Retrieved 12/30/2013 from http://www.wipo.int/export/sites/www/freepublications/en/intproperty/941/wipo_pub_941_2013.pdf.

84. Author, 2007.

85. Author, 2014. 


\section{Appendix: Research Methodology Overview}

Over the course of a decade, we conducted in-depth interviews of ERC leaders and participants, collected wide-ranging survey data, and studied extensive archival data on ERCs. During the first five years of the project, more than 135 hours were devoted to collecting qualitative data, with more than two hundred ERC leaders and participants interviewed. Approximately 2,300 research faculty, center directors, industry partnering managers,

administrative staff, graduate and undergraduate students, and postdoctoral researchers were invited to participate in an online survey, of which more than 800 responded. ERCs must annually report their financial and performance information to a third party company with which NSF contracts to collect, organize, and analyze ERC data; those archival data were collected for all active ERCs. During the last five years, we conducted in-depth case studies of three ERCs, which we showcased in our recently published book and used to focus in on the prescriptions of the Organized Innovation framework ${ }^{85}$.

ERCs are particularly helpful for understanding how to better manage innovation. For one, they have had much success, despite receiving less attention and funding than other programs (Feller et al., 2002; Roessner et al., 2010). Compared to \$7 billion allocations for NSF in 2011, ERCs received roughly \$1 billion total between 1985 and 2009 (National Science Foundation, 2013). The payoff on this investment across 50 ERCs has been estimated at well into the tens of billions of dollars in terms of downstream market value to the US economy ${ }^{49}$ (Lewis, 2010). Reasons for this success lie in the way the ERCs are organized and managed. These lessons inspired key aspects of the Organized Innovation framework. 


\section{Figure 1: Organized Innovation Framework}

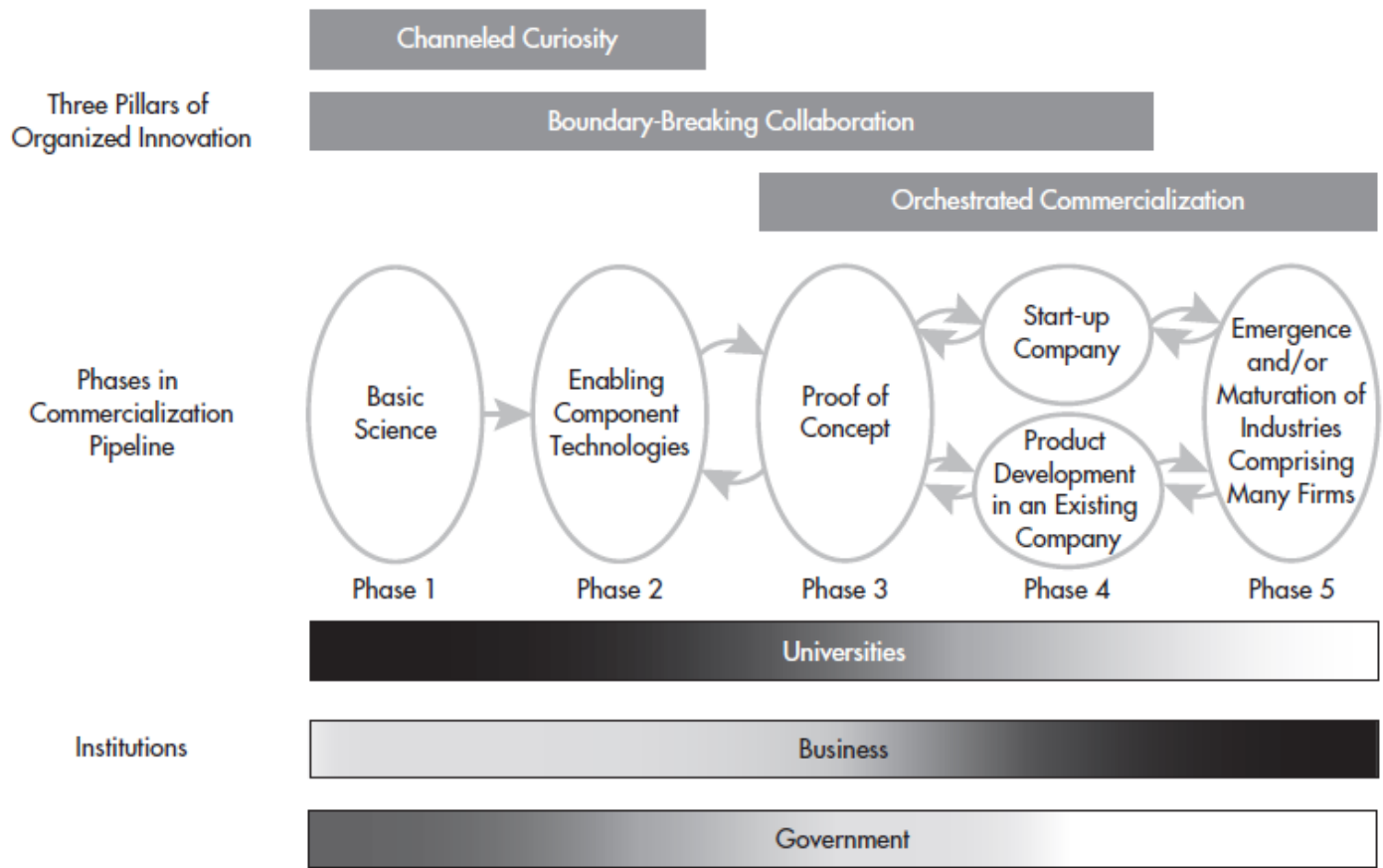

Low Involvement

High Involvement

Used with permission $^{85}$

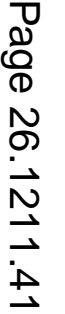

